\title{
Photothermolysis mediated by gold nanorods modified with EGFR monoclonal antibody induces Hep-2 cells apoptosis in vitro and in vivo
}

This article was published in the following Dove Press journal:

International Journal of Nanomedicine

17 April 2014

Number of times this article has been viewed

\author{
Shiwen Zhang ${ }^{1,2, *}$ \\ Yunlong $\mathrm{Li}^{3,4, *}$ \\ Xiaoguang $\mathrm{He}^{2}$ \\ Shouan Dong 5 \\ Yunchao Huang 6 \\ Xiaojiang $\mathrm{Li}^{\prime}$ \\ Yuxiao $\mathrm{Li}^{2}$ \\ Congguo $\mathrm{Jin}^{7}$ \\ Yingying Zhang ${ }^{8}$ \\ Yuanling Wang ${ }^{9}$
}

'Department of Head and Neck, The Third Affiliated Hospital of Kunming Medical University (Tumor Hospital of Yunnan Province), Kunming, ${ }^{2}$ Department of Head and Neck, The First Affiliated Hospital of Kunming Medical University, Kunming, ${ }^{3}$ Medical Faculty, Kunming University of Science and Technology, Kunming, ${ }^{4}$ The First People's Hospital of Yunnan Province (The Affiliated Hospital of Kunming University of Science and Technology), Kunming, ${ }^{5}$ Kunming Institute of Precious Metals, Kunming, ${ }^{6}$ Department of cardiothoracic surgery, The Third Affiliated Hospital of Kunming Medical University (Tumor Hospital of Yunnan Province), Kunming, ${ }^{7}$ Institute of Oncology, The Third Affiliated Hospital of Kunming Medical University (Tumor Hospital of Yunnan Province), Kunming, ${ }^{8}$ Clinical skills training center of Kunming Medical University, Kunming, 'Department of Anesthesiology, Yan An Hospital, Kunming, Yunnan, The People's Republic of China

*These authors contributed equally to this work

Correspondence: Xiaoguang He Department of Head and Neck, The First Affiliated Hospital of Kunming Medical University, Kunming, Yunnan 650032,

People's Republic of China

Tel +868715324888

Fax+8687I 5324888

Email hexg1018@163.com
Abstract: Gold nanorods (AuNRs) have been used in plasmonic photothermal therapy (PPTT), which is thought to be more efficient and selective than conventional photothermal therapy. The efficiency and safety of PPTT can be improved by functionally modifying the gold nanorods with proteins or biomolecules. In this study, AuNRs were modified with antiepidermal growth factor receptor (EGFR) monoclonal antibody (mAb), and the apoptotic potential of EGFRmAb-AuNR was assessed in Hep-2 cells in vitro and in vivo. The EGFRmAb modification had no obvious influence on the original optical property of the AuNRs, but it significantly increased the entry of AuNRs into Hep-2 cells. EGFRmAb-AuNRs, with appropriate laser irradiation, resulted in higher Hep-2 cells apoptosis than AuNRs did alone, in vitro, and was accompanied by alteration of reactive oxygen species (ROS) production, $\mathrm{Ca}^{2+}$ release, change in mitochondrial membrane potential $(\Delta \Psi \mathrm{m})$, cytochrome $\mathrm{c}$ (Cyt-c) release, active caspase-3 expression, and level of B-cell lymphoma 2 (Bcl-2) and B-cell lymphoma 2 protein-associated X protein (Bax). EGFRmAb-AuNR-mediated apoptosis in Hep-2 cells was also observed in vivo and had an inhibitive effect on growth of Hep-2 tumor xenografts. Our data suggest that the EGFRmAb modification improves AuNR-mediated apoptosis and may have the potential to be used clinically.

Keywords: AuNRs, laryngeal squamous cancer cells, plasmonic photothermal therapy, PPTT

\section{Introduction}

Nano technology has been widely used in biomedical research in recent years. Gold nanorods (AuNRs) are a nontoxic nonmaterial and are thought to be a promising tool for use in clinical diagnosis and treatment of diseases. ${ }^{1,2}$ AuNRs have a characteristic surface plasmon resonance, ${ }^{2-5}$ with two distinctive absorption peaks: a longitudinal plasmon absorption peak and transverse plasmon peak (at around $520 \mathrm{~nm}$ ). The longitudinal plasmon peak locates in the far-red and near-infrared (NIR) region of the electromagnetic spectrum. In these regions, living tissues could be well penetrated by light located in far-red and near-infrared (NIR) region of the electromagnetic spectrum. In addition, the longitudinal plasmon peak can be altered by modifying the structure of the AuNRs, without changing the transverse plasmon peak. Due to the phenomenon of surface plasmon resonance, AuNRs have a higher light absorption in the NIR region than do conventional laser phototherapy agents. High light absorption in the NIR region is very important in photothermal therapy as it has the deepest penetration in tissue (known as "tissue optical window"). ${ }^{6}$ The gold nanospheres and gold nanoshells have shown a strong absorption in NIR, when their size and thickness, respectively, were controlled. ${ }^{4,7}$ Spheres with a diameter of $30 \mathrm{~nm}$ were found to be optimal for intracellular uptake. ${ }^{8}$ Therefore, the AuNRs (49.81 nm at length and $12.70 \mathrm{~nm}$ in diameter) 
described in this study are better than gold nanospheres and gold nanoshells with a larger size, as the bigger size of the nanospheres/nanoshells will reduce intracellular uptake of gold nanospheres or gold nanoshells. The light absorbed by AuNRs can subsequently convert into heat. ${ }^{2,3}$ Therefore, AuNRs have a great potential to be used in plasmonic photothermal therapy.

In the descriptions by Wang et al, ${ }^{9}$ AuNRs had a quick clearance in blood, and long-term retention of AuNRs were found in the reticuloendothelial system, in tissues such as liver, spleen, and kidney. In contrast, AuNRs in brain, muscle, and bone were drastically decreased 30 minutes after injection. AuNRs can be functionally modified with specific tumor-targeting molecules, ${ }^{10}$ such as antibodies. ${ }^{5,11,12}$ AuNRs conjugated with tumor-targeting antibody have been shown to selectively target cancer cells but not normal cells. ${ }^{1,10}$ Epidermal growth factor receptor (EGFR) is overexpressed in many cancer cells. ${ }^{13-16}$ Anti-EGFR antibodies have been used in targeting cancer cells with overexpression of EGFR. ${ }^{17-25}$ It is conceivable that anti-EGFR monoclonal antibody (EGFRmAb) conjugated with AuNRs (EGFRmAbAuNRs) could specifically target cancer cells and improve the selectivity and efficiency of AuNR-mediated photothermal cancer therapy. AuNRs enter into cells by diffusion. The entry of EGFRmAb-AuNRs into cells is mainly dependent on endocytosis, mediated by the binding between the conjugated EGFR antibody and EGFR on the cell membrane. EGFR expression varies among different cellular types. The method used to conjugate EGFRmAb onto the AuNRs influences the binding efficiency between the EGFRmAb-AuNR and EGFR. ${ }^{1}$ Thus, the effects of EGFRmAb-AuNRs might vary in different studies due to the above factors.

Laryngeal cancer is one of the most malignant tumors of the head and neck. ${ }^{26,27}$ Laryngeal squamous cell cancer (LSCC) is the most common type of laryngeal cancer. Lymph node metastasis and distant metastasis have been observed in patients with laryngeal squamous cell cancer, ${ }^{28,29}$ leading to a poor survival. Chemotherapy, surgery, and radiotherapy are now used to treat laryngeal cancer. ${ }^{30-32}$ These therapies are proved to be effective for laryngeal cancer, but they also bring several side effects for patients. LSCC cases mostly have high levels of EGFR expression. High EGFR expression has been shown to be associated with poor survival in patients with LSCC. ${ }^{33-35}$ Therefore, the targeted killing of LSCC cells with high expression of EGFR might be an effective way to treat LSCC. Intracellular hyperthermia mediated by AuNRs has been proved to effectively kill cancer cells. ${ }^{1}$ More recent studies have showed, that AuNRs can be modified with specific tumor-targeting antibodies to enhance their specificity in therapy. ${ }^{10}$ AuNRs modified with EGFRmAb specifically target the cells with EGFR expression. ${ }^{36}$ With development of nanotechnology, photothermal therapy using EGFRmAb-AuNR may be a new effective therapy for the treatment of LSCC.

Since EGFR is overexpressed in LSCC cells, ${ }^{33,34}$ in this study, EGFRmAb-AuNR was synthesized and used to induce Hep-2 cell (human LSCC cells) apoptosis in vitro and in vivo, and the possible apoptotic mechanism was investigated at the cellular level.

\section{Materials and methods Synthesis of EGFRmAb-AuNR conjugates}

AuNRs were provided by the Kunming Institute of Precious Metals (Kunming, People's Republic of China). AuNRs were prepared using seeded growth conditions, described elsewhere. ${ }^{37-39}$ The longitudinal plasmon resonances of AuNRs centered at $800 \mathrm{~nm}$. To prepare the EGFRmAbAuNRs conjugates, a $250 \mu \mathrm{L}$ colloidal solution $(0.4 \mathrm{nmol} / \mathrm{L})$ of poly(sodium 4-styrenesulfonate)-modified AuNRs and 1 $\mu \mathrm{L}(25.7 \mathrm{mg} / \mathrm{mL}$ ) EGFRmAb (Sigma-Aldrich, St Louis, MO, USA) were mixed and oscillated for 30 minutes. Then, the solution was centrifuged for 10 minutes at $12,000 \mathrm{rpm}$, and the sediments of EGFRmAb-AuNR conjugate were dissolved with phosphate-buffered saline (PBS). The synthetic AuNRs $(0.1 \mathrm{nmol} / \mathrm{L})$ were observed under transmission electron microscope (TEM) (JEM 1010; JEOL Ltd, Tokyo, Japan) to determine the mean value of the long and transverse diameter of the AuNRs. The absorption spectra of the AuNRs and EGFRmAb-AuNRs were determined by using ultravioletvisible (UV-vis)-NIR spectrometer (Lambda 900; PerkinElmer Inc., Waltham, MA, USA). A diode laser K81S09F (WT Beijing Ltd, Beijing, People's Republic China), at 808 $\mathrm{nm}$, was used for the laser irradiation experiment. The red laser, at $808 \mathrm{~nm}$, was focused to a $1 \mathrm{~mm}$ diameter spot on the sample.

\section{Cell culture, TEM, and inductively coupled plasma atomic emission spectroscopy element analysis}

Hep-2 cells were cultured in Dulbecco's Modified Eagle's Medium containing $10 \%$ fetal bovine serum and $1 \%$ penicillin-streptomycin (Life Technologies, Carlsbad, CA, USA), at $37^{\circ} \mathrm{C}$ with a humidified atmosphere containing $5 \%$ $\mathrm{CO}_{2}$. For the TEM analysis, Hep-2 cells were incubated with $0.1 \mathrm{nmol} / \mathrm{L}$ AuNRs or $0.1 \mathrm{nmol} / \mathrm{L}$ EGFRmAb-AuNRs for 6 hours before collection. Hep-2 cells were also treated with the combination of AuNRs plus laser (AuNRs+Laser) or EGFRmAb-AuNRs plus laser (EGFRmAb-AuNRs+Laser), 
and at 24 hours after the laser treatment, the irradiated cells were collected for the analysis. Cells were collected by 800 rpm centrifugation and fixed with $3.5 \%$ glutaraldehyde. The fixed cells were examined under TEM (JEM-1010, JEOL Company, Japan). Similarly, cells were incubated with $0.1 \mathrm{nmol} / \mathrm{L}$ AuNRs or $0.1 \mathrm{nmol} / \mathrm{L}$ EGFRmAb-AuNRs for 6 hours before the element analysis using inductively coupled plasma atomic emission spectroscopy (ICPAES) (Lambda900). A 3-(4,5-Dimethylthiazol-2-yl)-2,5diphenyltetrazolium bromide (MTT) assay was used to analyze Hep-2 cell proliferation under different stimuli. The EGFR-expression of Hep-2 cells and LSCC patient samples were examined by western blot. The samples $(n=36)$ of LSCC and adjacent tissue, and of normal laryngeal tissues $(n=13)$ were collected from the First and the Third Affiliated Hospital of Kunming Medical University. The ethics committee of Kunming Medical University approved this study in using human and mouse tissues.

\section{Western blot}

The whole-cell or whole-tissue lysate were prepared using protein lysis buffer (Beyotime, P0013). Briefly, equal protein/lane was separated by sodium dodecyl sulfate polyacrylamide gel electrophoresis and then blotted onto a polyvinylidene difluoride immobilon membrane (EMD Millipore, Billerica, MA, USA). The membrane was incubated with the solution of diluted primary antibodies $(1: 000 \mathrm{v} / \mathrm{v})$ overnight at $4{ }^{\circ} \mathrm{C}$. Subsequently, the membrane was incubated with the peroxidase-conjugated anti-rabbit (KPL, 474-1506, 1:5000) immunoglobulin G for 1 hour at room temperature. The enhanced chemiluminescence western blot detection kit (Millipore, WBKLS0500) was used to detect the epitope.

\section{Apoptosis assay}

Hep-2 cells were cultured in 24-well plates and treated with 0.1 nmol/L AuNRs or $0.1 \mathrm{nmol} / \mathrm{L}$ EGFRmAb-AuNRs for 6 hours before the irradiation. The irradiated cells were collected at 0 hours, 24 hours, 48 hours, and 72 hours postirradiation. The collected cells were fixed with $3.5 \%$ glutaraldehyde. Apoptosis was analyzed using two methods: TEM and flow cytometry (FCM). TEM was used to observe the ultrastructure of the tumor cells. Terminal deoxynucleotidyl transferase dUTP nick end labeling (TUNEL)/Propidium Iodide (PI) FCM was the method used to determine the apoptosis and cell cycle distribution of the treated Hep-2 cells. Cells were harvested using a trypsin/ethylenediaminetetraacetic acid mixture, and then, cells $\left(1 \times 10^{6}\right)$ were fixed with $4 \%$ paraformaldehyde for 30 minutes at $4^{\circ} \mathrm{C}$. After that, cells were washed twice with PBS and then, fixed with $70 \%$ ethanol overnight at $-20^{\circ} \mathrm{C}$. Cells were then rehydrated and stained with TUNEL Label Mix (F. Hoffman-La Roche Ltd, Basel, Switzerland) for 60 minutes at $37^{\circ} \mathrm{C}$ in a humidified atmosphere, in darkness. Cells were then washed with PBS and treated with $100 \mathrm{U} / \mathrm{mL}$ RNase (R6148, Sigma-Aldrich) containing $0.002 \%$ Triton $^{\mathrm{TM}}$ X 100 (Sigma-Aldrich) for 15 minutes before staining with PI (final concentration $50 \mu \mathrm{g} / \mathrm{mL}$ ) (cIEF pI Marker Kit; Beckman Coulter Inc., Brea, CA, USA) for 20 minutes. The treated cells were then analyzed by FACScan $\left(\right.$ Coulter $^{\circledR}$ Epics $^{\circledR}$ XL $^{\mathrm{TM}}$ Flow Cytometer; Beckman Coulter Inc.). For the FACScan analysis of xenograft tumor cells, tumors in nude mice were excised and homogenized in lysis buffer (RIPA Lysis Buffer System/sc-24948; Santa Cruz Biotechnology Inc., Dallas, TX, USA) by grinding with a pestle. The homogenates were then passed through a $70 \mu \mathrm{M}$ cell strainer to get single-cell suspensions, which were then analyzed by the previously described TUNEL/PI FCM method. Meanwhile, FCM was used to analyze other apoptotic molecules, including cytochrome c (Cyt-c) (CBA077 InnoCyte ${ }^{\text {TM }}$ Flow Cytometric Cytochrome c Release Kit/CBA077-1KIT; EMD Millipore), change in mitochondrial membrane potential $(\Delta \Psi \mathrm{m})$ (Mitochondria staining kit (JC-1)/125T; MultiSciences Biotech Company, People's Republic of China), B-cell lymphoma 2 protein (Bcl-2) (Bcl2 Mouse Anti-Human mAb [clone Bcl2/100]), FITC conjugate/A15764; Life Technologies), Bcl-2-associated $\mathrm{X}$ protein (Bax) (LifeSpan BioSciences Inc.), $\mathrm{Ca}^{2+}$ (Calcium Green $^{\mathrm{TM}}-1 / \mathrm{C}-3012$; Life Technologies), reactive oxygen species (ROS) (Reactive Oxygen Species Assay Kit/S0033; Beyotime Co, Jiangsu, People's Republic of China) and caspase-3 (BD Biosciences, Franklin Lakes, NJ, USA).

\section{Xenograft model of Hep-2 cells}

BALB/C nude mice (average weight 17-22 g, age 5-6 weeks) were purchased from Vital River Laboratories (Beijing, People's Republic of China) and housed with sterile food and water. Nude mice received subcutaneous injection with tumor cells $\left(2 \times 10^{7} / \mathrm{mL}\right)$. The palpable tumors were typically observed about 1 week after the injection of Hep-2 tumor cells. When the mean tumor volumes were $100 \sim 200 \mathrm{~mm}^{3}$, treatments were initiated. This consisted of $0.9 \% \mathrm{NaCl}$, AuNRs, or EGFRmAb-AuNRs injected through the tail vein. The injected dose of AuNRs in the AuNR group or EGFRmAb-AuNR group was $560 \mu \mathrm{g} / \mathrm{kg}$. The dosage for the in vivo study was fixed by referring to the description by Wang et al. ${ }^{9}$ In that study, Sprague Dawley rats were injected intravenously with AuNRs at a dose of $560 \mu \mathrm{g} / \mathrm{kg}$. The dosages were nontoxic to the mice used in this study. The combination of $0.9 \% \mathrm{NaCl}+\mathrm{Laser}$ served 
as a negative control, and cisplatin served as a positive control for analyzing the treatment effects of AuNRs+Laser or EGFRmAb-AuNRs+Laser on mouse tumor xenografts. Cisplatin $(5 \mathrm{mg} / \mathrm{kg})$ was administered by intraperitoneal injection twice a week (day 1 and day 3). An NIR laser was used to irradiate the tumor with a wavelength of $808 \mathrm{~nm}$. The irradiation power was $3.0 \mathrm{~W} / \mathrm{cm}^{2}$, and the irradiation time was 8 minutes. After 2 weeks, mice in different treatment groups were euthanized, and tumor tissues were collected. Tumor size was measured with a vernier caliper every 1 to 2 days (by investigators Yingying Zhang and Shiwen Zhang) after the irradiation. The volume was calculated using the formula:

$$
\mathrm{V}=\left(\mathrm{L} \times \mathrm{W}^{2}\right) / 2
$$

where $\mathrm{V}$ was the volume, $\mathrm{L}$ was the length, and $\mathrm{W}$ was the width. FCM was used to detect the apoptosis, necrosis, and expression of active caspase-3, Bcl-2, and Bax in tumor cells in the collected tumor tissues.

\section{In vivo apoptosis detection by hematoxylin and eosin or TUNEL staining}

Tumors in nude mice were excised and sectioned to $8 \mu \mathrm{m}$ thickness. In vivo apoptosis detection was performed using hematoxylin and eosin (H\&E staining and TACS ${ }^{\circledR} 2$ TdT-DAB In Situ Apoptosis Detection Kit (Trevigen, Inc., Gaithersburg, MD, USA). Apoptotic cells were detected by brown staining, with the TACS ${ }^{\circledR} 2$ TdT-DAB In Situ Apoptosis Detection Kit. Apoptotic cells in tumors were recorded under a light microscope ( $\times 400$ magnification) (Olympus CH30; Olympus, Tokyo, Japan). Ten randomly selected fields of entire tumor tissue were examined in the EGFRmAb-AuNRs+Laser treatment group.

\section{Results}

\section{Characterization of EGFRmAb-AuNRs}

To characterize the AuNRs, TEM analysis was used. The results of the TEM analysis showed that $0.1 \mathrm{nmol} / \mathrm{L}$ AuNRs had good stability and dispersion (Figure 1A). The particle size of the AuNRs was uniform (49.81 nm in length and $12.70 \mathrm{~nm}$ in diameter), the aspect ratio was 3.92. UV-visNIR spectrometer analysis showed that $0.1 \mathrm{nmol} / \mathrm{L}$ AuNRs had two resonance absorption peaks: a transverse peak at $510 \mathrm{~nm}$ and a longitudinal peak at $800 \mathrm{~nm}$ (Figure 1A). After being modified by EGFRmAb, the longitudinal resonance absorption peaks of AuNRs had a red shift of 7-9 nm, which did not change the original optical properties (Figure 1A).
The same amounts, $0.1 \mathrm{nmol} / \mathrm{L}$ AuNRs and $0.1 \mathrm{nmol} / \mathrm{L}$ EGFRmAb-AuNRs, were used in all in vitro experiments as in this concentration, AuNRs and EGFRmAb-AuNRs had good absorbance and stability.

EGFR was expressed in Hep-2 cells (Figure 1B). Meanwhile, EGFR was found to be highly expressed in the LSCC tissues ( $n=36)$ but not in the normal laryngeal tissues $(n=13)$. A representative image of EGFR expression in the LSCC patients is shown in Figure 1B. Therefore, Hep-2 cell was suitable for studying EGFR-targeted LSCC therapy. The results from the TEM observation showed that AuNRs entered into Hep-2 cells after being treated with AuNRs for 6 hours (Figure 1C). In the experiments described below, Hep-2 cells were treated with AuNRs or EGFRmAb-AuNRs for 6 hours before subsequent treatments. The treatment with AuNRs did not obviously change cellular shape and cellular structure. ICP-AES element analysis showed that the number of AuNRs in cells modified by EFGRmAb was more than that with nonmodification (Figure 1D). We also found that EGFRmAb-AuNRs accumulated on the membrane of Hep-2 cells (Figure S1). The result indicated that the EGFRmAb-AuNRs targeted the EGFR-expressing tumor cells. Generally, the EGFRmAb modification allowed more AuNRs to enter Hep-2 cells.

The room temperature in our lab was maintained at $23^{\circ} \mathrm{C}$ in this study. We irradiated $0.1 \mathrm{nmol} / \mathrm{L}$ AuNRs with a diode laser $(808 \mathrm{~nm})$ at various power densities $\left(0-5 \mathrm{~W} / \mathrm{cm}^{2}\right)$. During the continuous irradiation, the solutions' temperature quickly rose at the beginning and then became stable. We found $3 \mathrm{~W} / \mathrm{cm}^{2}$ laser irradiation resulted in a solution temperature that rose and stabilized at $46^{\circ} \mathrm{C}$. In our experiment, cells treated with AuNRs or EGFRmAb-AuNRs were also irradiated with $3 \mathrm{~W} / \mathrm{cm}^{2}$ laser for 8 minutes $\left(46^{\circ} \mathrm{C}\right)$. The irradiated cells were stained with $0.4 \%$ trypan blue, and about $70 \% \sim 80 \%$ cells were stained blue (indicating they were dead). According to the formula

$$
\mathrm{D}=\mathrm{tR}^{\mathrm{T}=43,36},
$$

treatment of cells with $46^{\circ} \mathrm{C}$ for 8 minutes is approximately equal to the treatment of cells with heat $\left(43^{\circ} \mathrm{C}\right)$ for 60 minutes. This is clinically reasonable. Where D represents thermal dose; $t$ represents exposure time; $T$ represents given temperature; and $\mathrm{R}$ represents a constant.

After irradiation with NIR laser, AuNRs or EGFRmAbAuNRs leads to Hep-2 cell growth inhibition and apoptosis (Figure 2A). NIR laser irradiation caused a quick temperature rise in the solution of AuNRs or EGFRmAb-AuNRs (Figure 2B). The cytotoxic effect of EGFRmAb-AuNRs was 
A

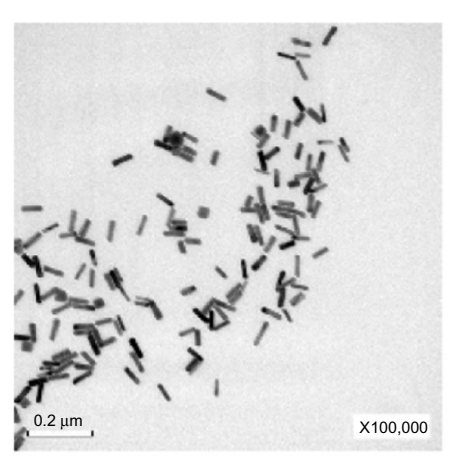

AuNRs

B

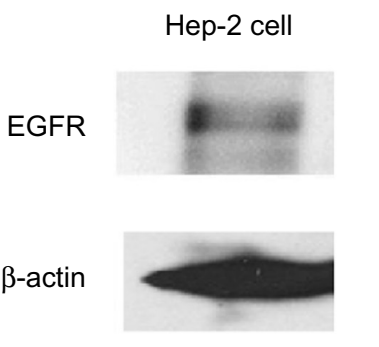

EGFR

$\beta$-actin

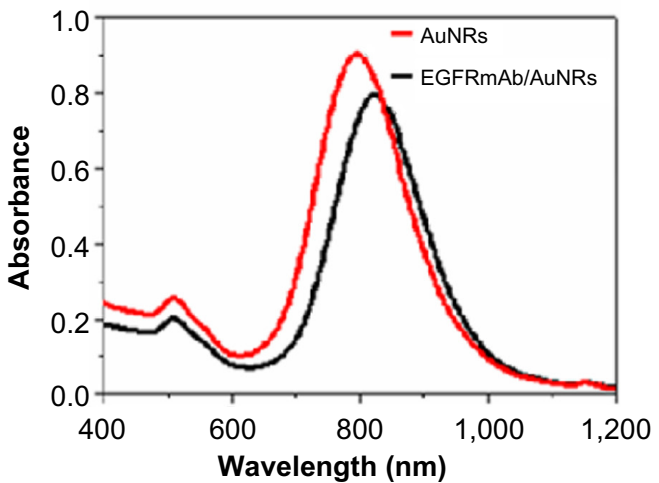

Normal Tissues Laryngeal

laryngeal adjacent to squamous cell

tissue LSCC cancer (LSCC)
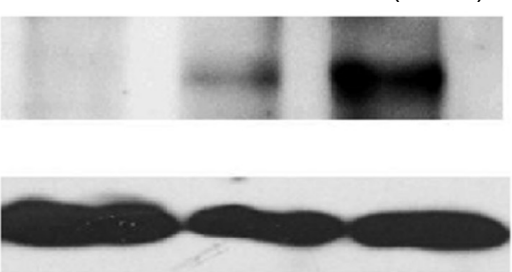

\section{C}
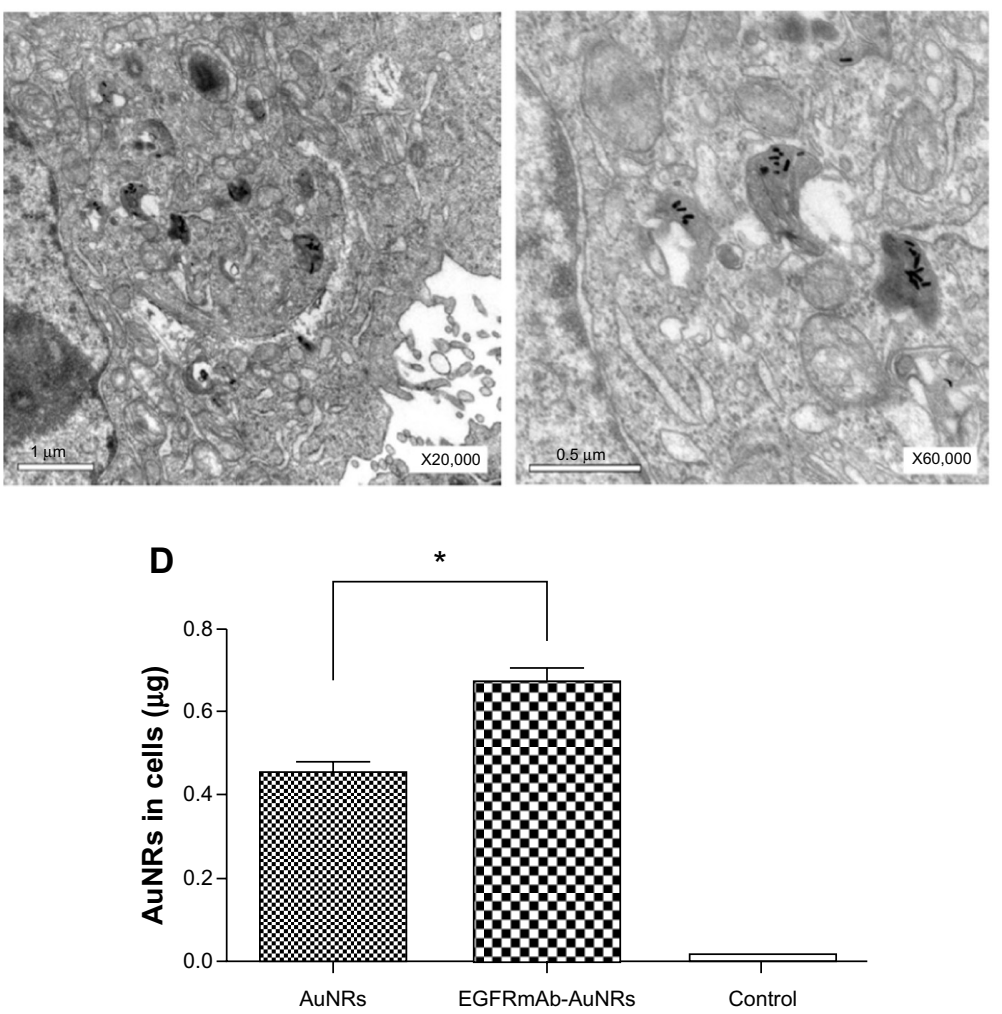

Figure I (A) Optical absorption spectra and TEM images of AuNRs. (B) Expression of EGFR in Hep-2 cells (left). Expression of EGFR in the patient samples of normal laryngeal tissue, tissue adjacent to LSCC, and LSCC tissue (right). (C) TEM images of Hep-2 cells treated with EGFRmAb-AuNRs. (D) ICP-AES element analysis of Hep-2 cells treated with AuNRs or EGFRmAb-AuNRs (Student's $t$-test, $* P<0.05$ ).

Note: Results represent one of three replicates.

Abbreviations: AuNRs, gold nanorods; EGFR, epidermal growth factor receptor; EGFRmAb, anti-EGFR monoclonal antibody; ICP-AES, inductively coupled plasma atomic emission spectroscopy; LSCC, laryngeal squamous cell cancer; TEM, transmission electron microscope. 
evaluated in Beas-2B cells (human bronchial epithelial cells) and Hep- 2 cells. The Beas-2B cells and Hep-2 cells were treated with various doses of EGFR-AuNRs or 0.1 AuNRs for 72 hours. The results of the MTT assay (Figure 2C) showed that $0.1 \mathrm{nmol} / \mathrm{L}$ EGFRmAb-AuNRs or AuNRs had little cytotoxicity to Beas-2B cells and Hep-2 cells.

\section{Effects of EGFRmAb-AuNRs on apoptosis}

To determine whether the Hep-2 cells growth inhibition mediated by AuNRs or EGFRmAb-AuNRs was associated with apoptosis, TEM and FCM were used. The results of the TEM showed obvious Hep-2 cell apoptosis after irradiation for 48 hours in the AuNRs+Laser group and EGFRmAbAuNRs+Laser group (Figure3A). In the AuNRs+Laser group, cell shrinkage, chromatin condensation along the nuclear membrane, membrane blebbing, and formations of apoptotic bodies could be found (Figure 3A, left panel). In the EGFRmAb-AuNRs+Laser group, cell shrinkage, nuclear fragmentation, and chromatin condensation along the nuclear membrane could be found (Figure 3A, right panel). TEM images from both groups (Figure 3A) showed the characteristic morphological and ultrastructural changes of apoptosis. In the FCM analysis, the apoptosis rate of the EGFRmAb-AuNRs+Laser group ( $\sim 50 \%$ at 48 hours and $\sim 73 \%$ at 72 hours) was higher than that of the AuNRs+Laser group $(-32 \%$ at 48 hours and $\sim 52 \%$ at 72 hours) (Figure $3 \mathrm{~B}$ ). In the cell cycle distribution analysis by FCM, the proportion of G0/G1 cells significantly increased to $\sim 70 \%$ and $\sim 80 \%$, respectively, after treatment with AuNRs+Laser or EGFRmAb-AuNRs+Laser for 48 (Figure 3C). The alteration of several apoptotic markers (caspase-3, Bax, ROS, $\mathrm{Ca}^{2+}, \Delta \Psi \mathrm{m}$, and Bcl-2) was shown in the EGFRmAb-AuNRs+Laser group (Figure 4).

\section{Effects of EGFRmAb-AuNRs on treatment of tumor xenograft}

Xenograft tumor models of nude mice were used to analyze the treatment effects of AuNRs+Laser and EGFRmAbAuNRs+Laser. The growth of tumor was suppressed in both treatment groups (Figure 5A). However, treatment with lowdose NIR laser irradiation did not suppress the tumor growth. Treatment with cisplatin served as a positive control; after treatment with cisplatin for 2 weeks, the tumor growth in nude mice was significantly suppressed. In each treatment group, six mice were used. The photos of tumor xenografts in Figure $5 \mathrm{~A}$ were all taken at 14 days after the laser irradiation or cisplatin treatment. FCM analysis showed that the apoptosis rate in the EGFRmAb-AuNRs group ( $-32 \%)$ was higher than that in the AuNRs group ( 10\%) (Figure 5B). FCM analysis of transplanted tumors in mice further confirmed that the apoptosis was induced by phototherm is of AuNRs or EGFRmAb-AuNRs in vitro. We also detected the expression of active caspase-3, Bax, and Bcl-2 in all the vitro tumors $(n=6)$ that were collected at 14 days postirradiation. The expression alteration of active caspase-3, Bax, and Bcl-2 in the in vitro tumors showed a similar trend to that of the in vitro cellular studies (Figure 4), as shown in Figure S2. The H\&E staining and TUNEL staining (Figure 5C) also supported the conclusion that EGFRmAb-AuNRs+Laser treatment induced apoptosis in transplanted Hep-2 cell tumors.

\section{Discussion}

AuNR-mediated photothermia has been shown to kill tumor cells. The therapeutic effects mediated by AuNRs are associated with size, shape, surface charge, and surface modification, which influence the effects of AuNR-intake by cells. Increasing intake of AuNRs can improve the efficiency of AuNR-mediated killing effects in tumor cells. In this study, AuNRs were modified with EGFRmAb. The EGFRmAb-AuNRs entered tumor cells to a greater extent than did AuNRs alone. Meanwhile, the possible mechanism of AuNR-mediated killing of Hep-2 cells was investigated in vitro and in vivo.

The EGFRmAb-AuNRs were characterized in our study (Figure 1). TEM showed that the AuNRs could easily enter Hep-2 cells and that AuNRs was mostly found in cellular organelles, such as lysosomes (Figure 1C). Based on these preliminary observations, it is possible that AuNRs have a tendency to locate in particular cellular organelles but are not randomly distributed. ICP-AES element analysis showed that a greater number of EGFRmAb-AuNRs than AuNRs, entered the Hep-2 cells. Therefore, the modification of AuNRs with EGFRmAb improved the efficiency of AuNRs, entry into Hep-2 cells, which might be associated with endocytosis. ${ }^{40}$ Only tumor tissues were collected from the mice injected with AuNRs or EGFRmAb-AuNRs. This was a weakness of our study. The distribution of AuNRs or EGFRmAb-AuNRs is very important for the future study of their mechanisms.

The size of AuNRs in this study was $49.81 \mathrm{~nm}$ in length and $12.70 \mathrm{~nm}$ in diameter. Their aspect ratio was 3.92. The AuNRs absorbed strongly in the NIR (Figure 1A). The EGFRmAb-AuNRs showed a red shift of 7-9 nm (Figure 1A). The red shift was caused by the preferential assembly of the EGFRmAb-AuNRs, and these results are consistent with other studies ${ }^{23,41}$ in which conjugation of 


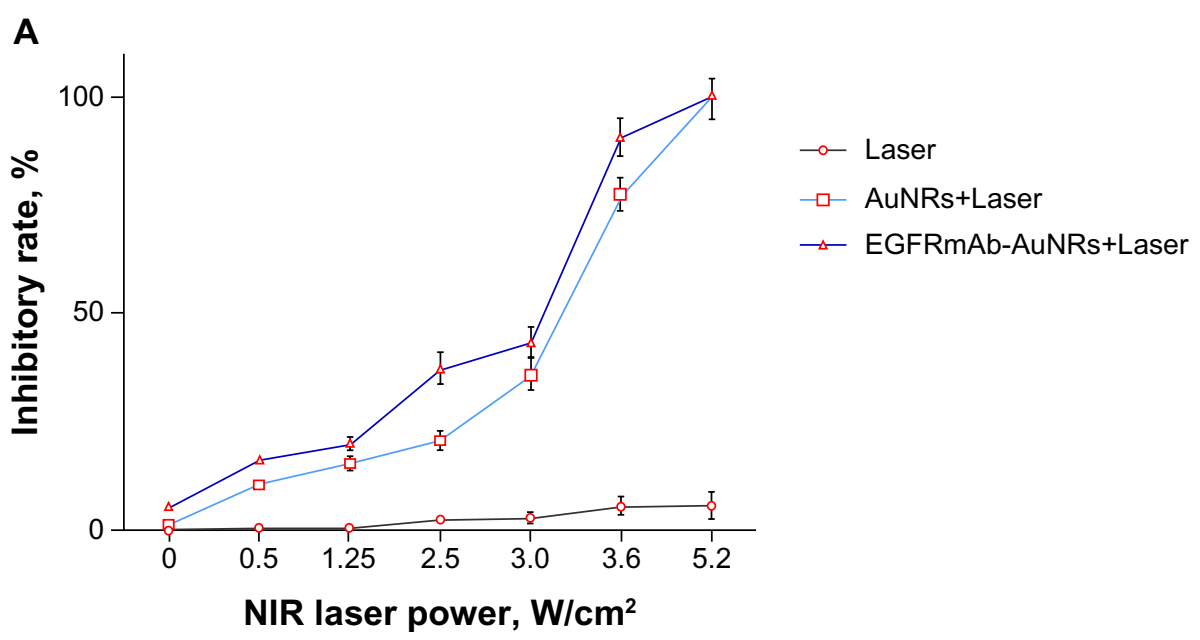

B

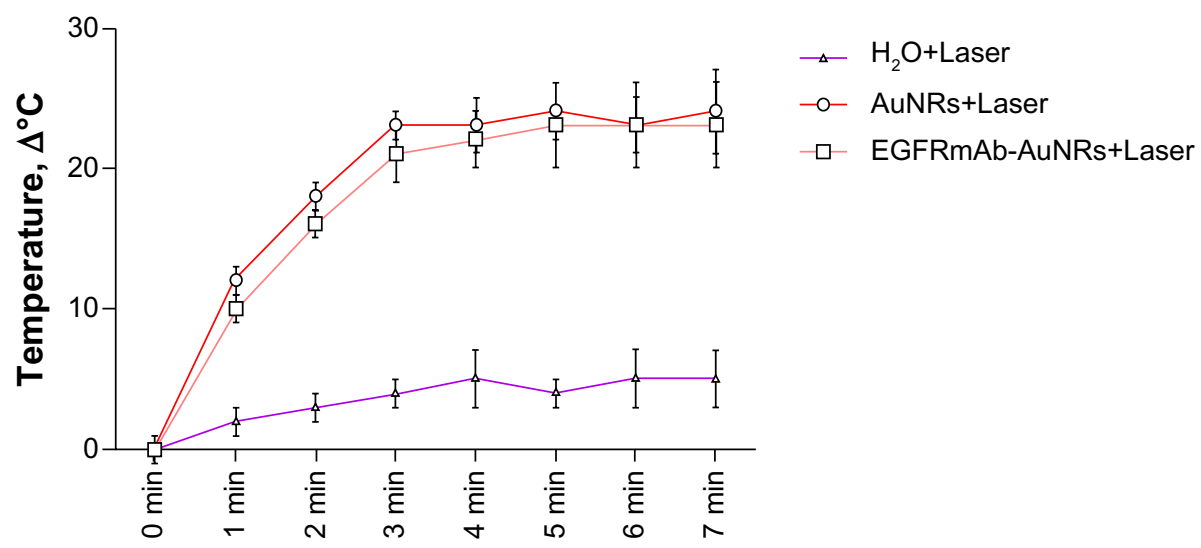

Time point, NIR $3.0 \mathrm{~W} / \mathrm{cm}^{2}$, Au $0.1 \mathrm{nM}$

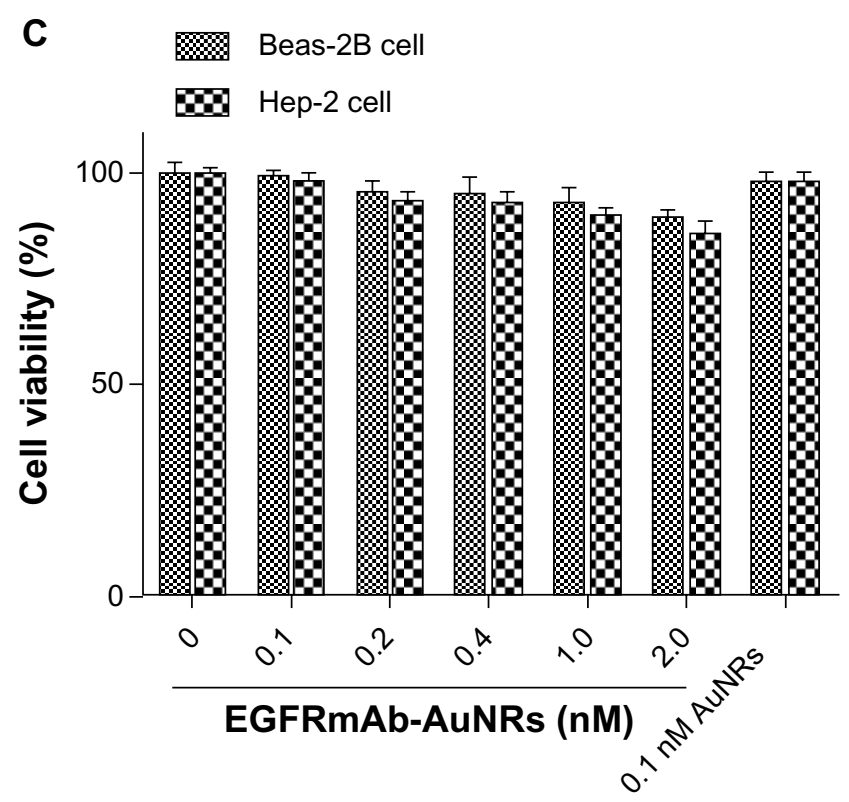

Figure 2 (A) Effects of EGFRmAb-AuNRs+Laser on Hep-2 cell growth. (B) Temperature change of different AuNR solutions after laser irradiation. Results represent one of three replicates. (C) The cytotoxic effects of various doses of EGFRmAb-AuNRs or 0.I nM AuNRs on Beas-2B cells and Hep-2 cells.

Abbreviations: AuNRs, gold nanorods; EGFR, epidermal growth factor receptor; EGFRmAb, anti-EGFR monoclonal antibody; NIR, near-infrared. 
A
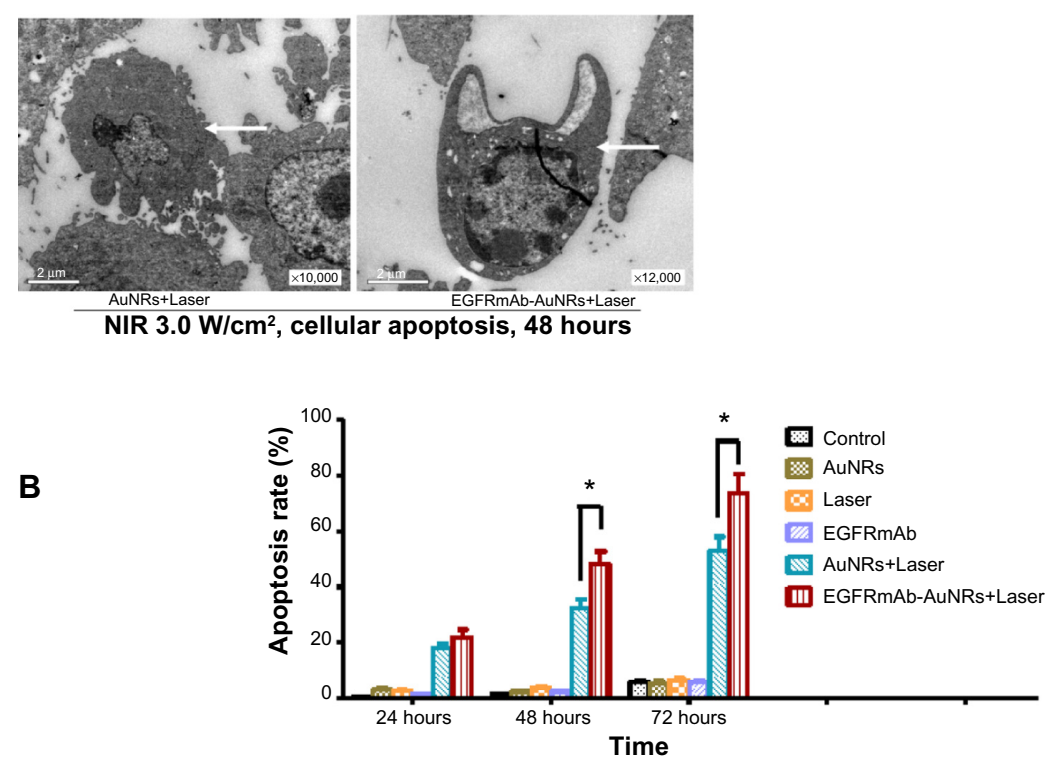

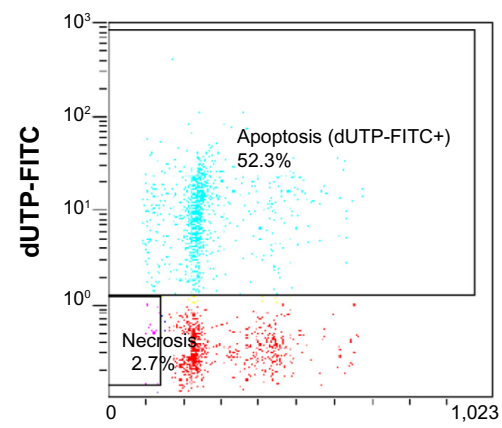

PI

AuNRs+Laser 72 hours

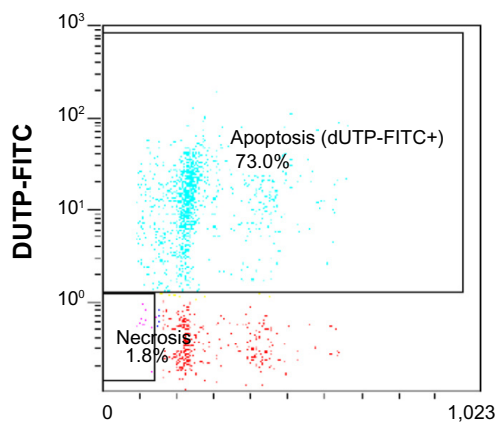

PI

EGFRmAb-AuNRs+Laser 72 hours

C

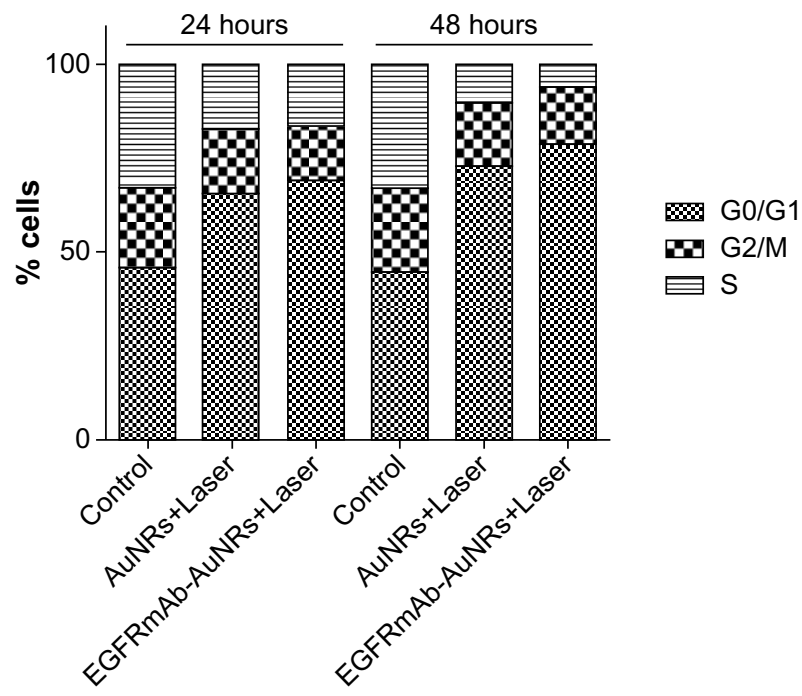

Figure 3 (A) TEM images of Hep-2 cells apoptosis after treatment of AuNRs+Laser or EGFRmAb-AuNRs+Laser. (B) FCM analysis of Hep-2 cell apoptosis at different time points ( 24 hours, 48 hours, and 72 hours) after treatment with AuNRs+Laser or EGFRmAb-AuNRs+Laser (Student's $t$-test, *P<0.05). (C) FCM analysis of cell cycle distribution in different treatment groups. Compared with control group, G0/GI cells significantly increased after treatment with AuNRs+Laser or EGFRmAb-AuNRs+Laser for 24 hours and 48 hours. Notes: Student's $t$-test, $P<0.05$. Results represent one of three replicates.

Abbreviations: AuNRs, gold nanorods; dUTP-FITC, 2"-deoxyuridine-5"-triphosphate-fluorescein isothiocyanate; EGFR, epidermal growth factor receptor; EGFRmAb, anti-EGFR monoclonal antibody; FCM, flow cytometry; NIR, near-infrared; PI, propidium iodide; TEM, transmission electron microscope. 
A
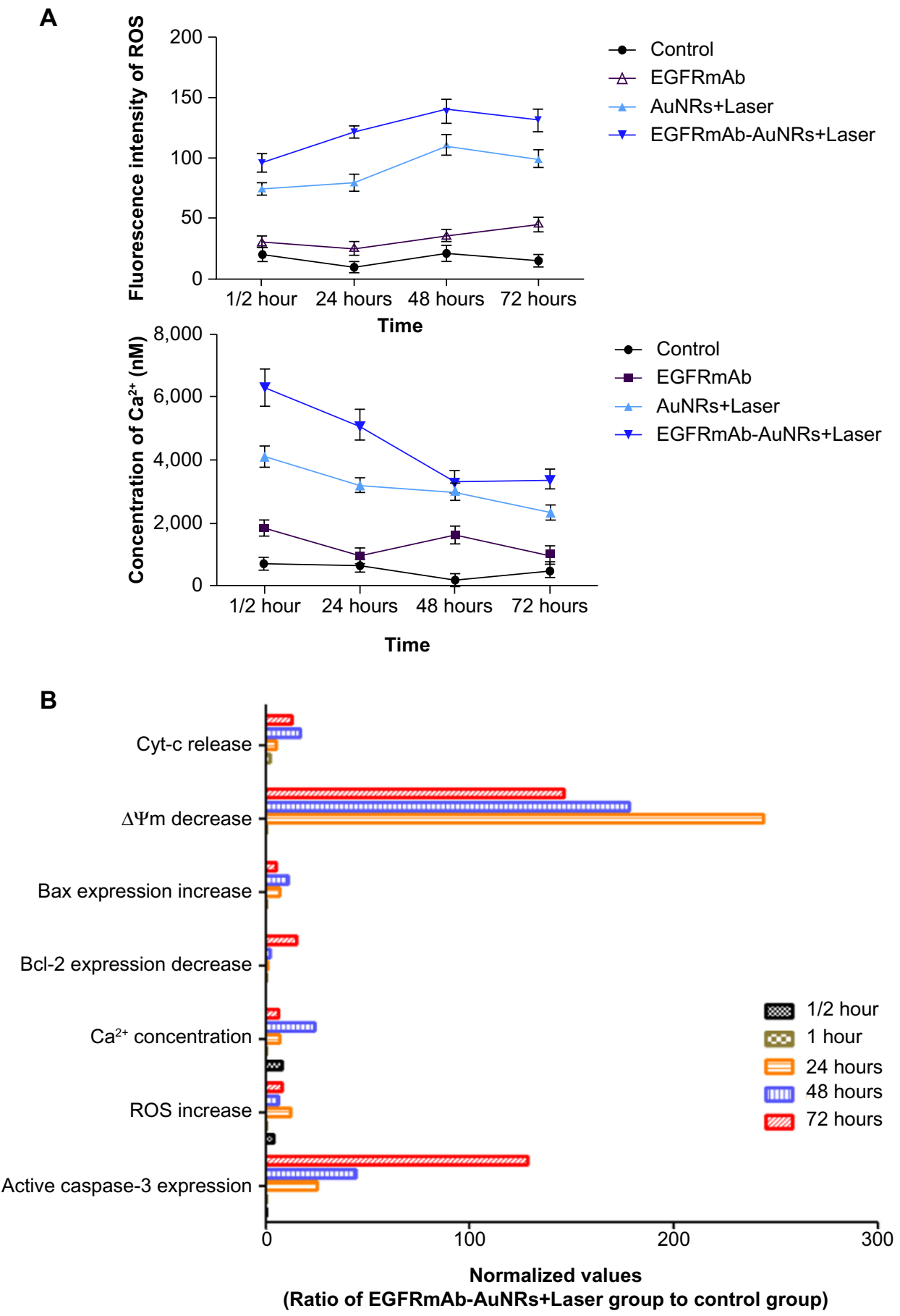

Figure 4 (A and B) Effects of EGFRmAb-AuNRs+Laser treatment on caspase-3, Bax, ROS, Ca ${ }^{2+}, \Delta \Psi \mathrm{m}$, and Bcl-2 in Hep-2 cells.

Note: Results represent one of three replicates.

Abbreviations: $\triangle \Psi \mathrm{m}$, change in mitochondrial membrane potential; AuNRs, gold nanorods; Bax, Bcl-2-associated X protein; Bcl-2, B-cell lymphoma 2 protein; Cyt-c, cytochrome c; EGFRmAb, anti-EGFR monoclonal antibody; ROS, reactive oxygen species.

AuNRs with antibodies resulted in a red shift compared with nonmodified AuNRs. EGFRmAb-AuNRs also had a strong absorption in the NIR. The EGFRmAb-AuNRs in this study are suitable for phototherapy. ${ }^{42}$

Cell death mediated by EGFRmAb-AuNRs+Laser treatment is closely associated with thermal production after NIR laser irradiation. ${ }^{2}$ In our study, the thermal production with
EGFRmAb-AuNRs+Laser treatment was measured by the temperature change during the NIR laser irradiation. It is noted that the temperature of the EGFRmAb-AuNRs+Laser solution stabilized after continuous NIR irradiation for a certain time (Figure 2).

The apoptotic characteristics of Hep-2 cells treated with AuNRs+Laser or EGFRmAb-AuNRs+Laser are shown 
A

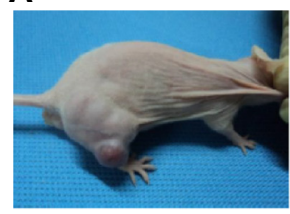

$0.9 \% \mathrm{NaCl}$ IV+Laser

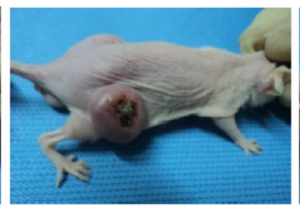

AuNRs IV+Laser EGFRmAb-AuNRs IV+Laser

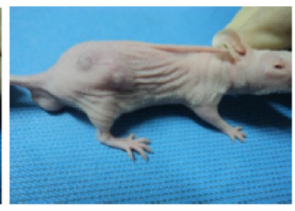

Cisplatin IP

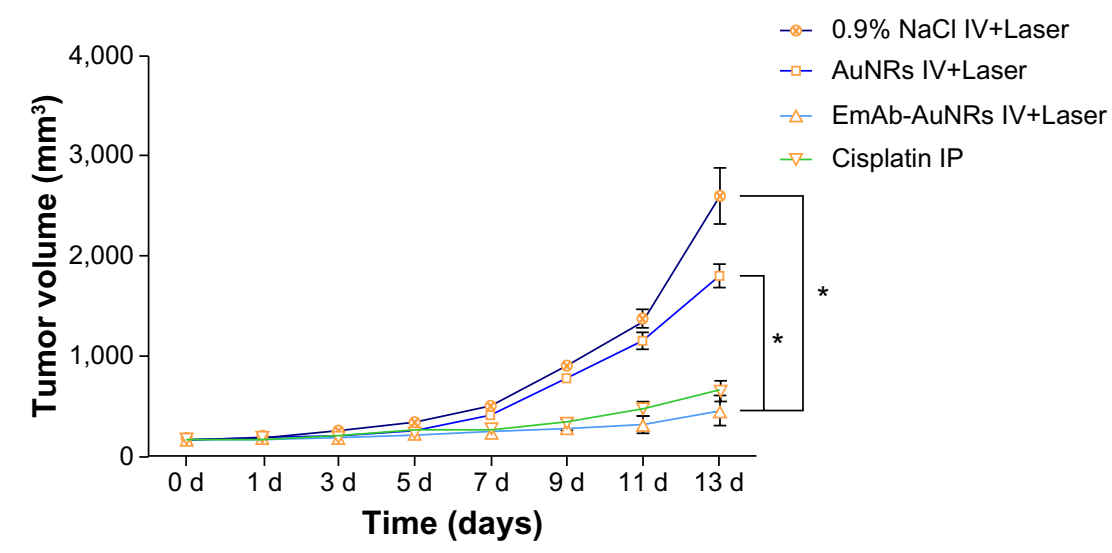

B

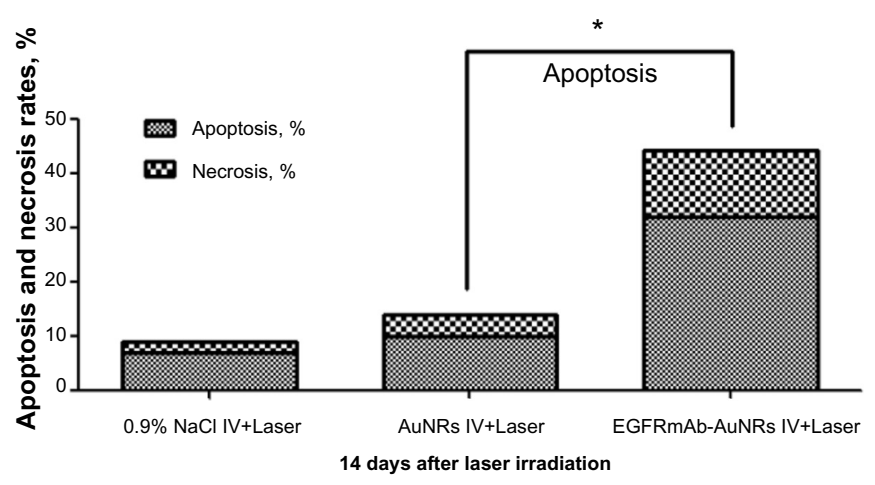

C

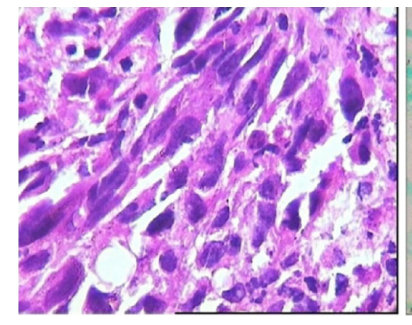

EGFRmAb-AuNRs+Laser (H\&E staining)

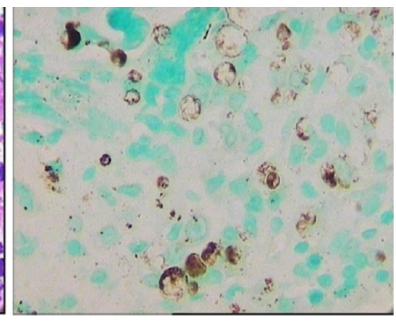

EGFRmAb-AuNRs+Laser (TUNEL staining)

Figure 5 (A-C) Effects of EGFRmAb-AuNRs+Laser treatment on xenograft tumors of Hep-2 cells (Student's $t$-test, ${ }^{*} \boldsymbol{P}<0.05$ ).

Notes: The animal pictures show representative xenograft tumors after treatment with AuNRs+Laser or EGFRmAb-AuNRs+Laser for 13 days. Results represent one of two replicates.

Abbreviations: AuNRs, gold nanorods; EGFR, epidermal growth factor receptor; dUTP, 2"-deoxyuridine-5"-triphosphate; EGFRmAb, anti-EGFR monoclonal antibody; H\&E, hematoxylin and eosin; IP, intraperitoneal; IV, intravenous; TUNEL, terminal deoxynucleotidyl transferase dUTP nick end labeling.

in Figure 3A. The results should be further validated by other in vivo experiments. This will provide more details of the apoptosis induced by AuNRs+Laser or EGFRmAbAuNRs+Laser. Levels of caspase-3, Bax, ROS, $\mathrm{Ca}^{2+}$, $\Delta \Psi \mathrm{m}$, and Bcl-2 were found to be altered in EGFRmAbAuNRs+Laser-mediated cell death (Figure 4). Caspase-3 is an important executioner of apoptosis. ${ }^{43,44}$ Active caspase-3 expression increased with EGFRmAb-AuNRs+Laser treatment (Figure 4D). This result suggested that the EGFRmAb-AuNRs+Laser treatment induced Hep-2 cell apoptosis. $\Delta \Psi \mathrm{m}$ decrease, Bax-expression increase, Bcl-2expression decrease, and ROS increase were all detected in 
the EGFRmAb-AuNRs+Laser treatment group (Figure 4D). The result suggested that the apoptosis with EGFRmAbAuNRs+Laser was mitochondria-dependent. In the study by Rejiya et al, the combination of EGFRmAb-AuNRs with laser induced A431 cell apoptosis accompanied with ROS increase, $\Delta \Psi \mathrm{m}$ decrease, and activation of caspase- $3 .{ }^{23}$ Our findings are consistent with their results. ROS production has been found to be an "inducer" that can activate the subsequent apoptotic and antiapoptotic factors. ${ }^{45}$ ROS production was seen earlier than alterations of the other apoptotic markers (Figure 4). The data suggested that the apoptosis induced by EGFRmAb-AuNRs was ROSdependent, and that ROS generation might be required for subsequent activations of apoptotic factors, like caspase-3. In Figure 4B, active caspase-3-expression started at 24 hours after laser irradiation, which was generally consistent with the increase of Bcl-2 expression. In vivo experiments showed that EGFRmAb-AuNRs had therapeutic effects on Hep-2 transplant tumor in vivo, and this therapeutic effect was dependent on apoptosis (Figure 5). Furthermore, the apoptosis mediated by EGFRmAb-AuNRs+Laser was greater than that by the AuNRs in vitro and in vivo (Figure 5).

In Figure 2A, there was not a significant difference in growth inhibition between the bare AuNR group and the EGFRmAb-AuNR group. However, in Figure 3B, the overall cell death (ie, apoptosis plus necrosis [ 75\%]) induced by EGFRmAb-AuNRs was higher than that induced by the AuNRs ( $55 \%)$. From the data, it is likely that the cell death modes induced by AuNRs or EGFRmAb-AuNRs were different between the groups of AuNRs and EGFRmAb-AuNRs. Recent studies have demonstrated that autophagy is associated with hyperthermia. ${ }^{46-48}$ Some TEM images showed that there were a higher number of autophagic structures (vacuolar components and secondary lysosomes) in the AuNRs+Laser group than in the EGFRmAb-AuNRs+Laser group (Figure S3). Therefore, it is possible that the low overall cell death (apoptosis plus necrosis) in the AuNRs group was related to other modes of cell death, such as autophagy. The above speculations need further examination as our data is too limited to draw firm conclusions.

Since the photothermolysis with AuNRs or EGFRmAbAuNRs in our study was shown to be effective in killing Hep-2 cells, understanding the exact cellular location of AuNRs or EGFRmAb-AuNRs will be very important for the investigation of the mechanism of cell death induced by AuNRs or EGFRmAb-AuNRs. Therefore, in future study, the cellular location of AuNRs or EGFRmAb-AuNRs should be determined by various techniques, like fluorescence microscopy, with ICP determination of the gold content in cellular organelles.
The Hep-2 cell is a human LSCC line that expresses EGFR (Figure 1B). In our study, the cellular uptake of AuNRs with the EGFRmAb-AuNRs group was significantly higher than that with AuNRs group (Figure 1D). The result suggested that EGFRmAb-AuNRs specifically targeted Hep-2 cells that expressed EGFR. Our results from the xenograft model of Hep-2 cells showed that tumor growth suppression or apoptosis induced by treatment with EGFRmAb-AuNRs+Laser was significantly higher than that induced by AuNRs+Laser (Figure 5). Therefore, EGFRmAb-AuNRs have the potential to be used in LSCCtargeted therapy, especially for the LSCC patients that have high levels of EGFR expression. The results also suggested that EGFRmAb-AuNRs could possibly be given through intravenous injection in clinical trials before giving laser treatment. It should be noted that the long- and short-term toxicity of EGFRmAb-AuNRs is still unclear and should be carefully examined before using clinically. Generally, our study showed the possibility of treating LSCC using EGFRmAb-AuNRs. Further studies are needed to give more guidance on how to use appropriately in the clinical treatment of LSCC.

Traditional chemotherapy (eg, cisplatin) has been found clinically to have therapeutic effects on tumors. However, chemotherapy drugs do not only kill cancer cells but also kill normal cells. Therefore, chemotherapy can cause side effects, such as renal toxicity. Radiotherapy can cause damage to the tumor. At the same time, it also damages the surrounding normal tissue. In this regard, photothermal therapy mediated by EGFRmAb-AuNRs is better than the traditional chemotherapy or radiotherapy. EGFRmAbAuNRs can specifically target Hep-2 cells (cancer cells), yet will only kill Hep-2 cells and has no influence on normal cells. Furthermore, EGFRmAb-AuNRs showed little toxicity in vitro and in vivo.

In this study, the potential of EGFRmAb-AuNRs in cancer treatment was evaluated using Hep- 2 cells. The in vitro and in vivo results showed that the photothermolysis mediated by combination of EGFRmAb-AuNRs and NIR irradiation could effectively kill Hep-2 cells, and the cell death was mainly caused by apoptosis. Generally, EGFRmAb-AuNRs have the potential to be used in cancer treatment, and more studies are needed.

\section{Acknowledgment}

We would like to give thanks for the kind support of National Center for Nanoscience and Technology (NCNST, People's Republic of China). We also would like to express gratitude for the helpful suggestions of Dr Yong-gang Yao 
(Kunming Institute of Zoology, Chinese Academy of Science) and Dr Yan Li (Kunming Institute of Botany, Chinese Academy of Science). This study was supported by the National Natural Science Foundation of China (81160324) and Kunming University of Science and Technology (KKZ3201360025).

\section{Disclosure}

The authors report no conflicts of interest in this work.

\section{References}

1. Alkilany AM, Thompson LB, Boulos SP, Sisco PN, Murphy CJ. Gold nanorods: their potential for photothermal therapeutics and drug delivery, tempered by the complexity of their biological interactions. $A d v$ Drug Deliv Rev. 2012;64(2):190-199.

2. Ungureanu C, Kroes R, Petersen W, et al. Light interactions with gold nanorods and cells: implications for photothermal nanotherapeutics. Nano Lett. 2011;11(5):1887-1894.

3. Tong L, Wei Q, Wei A, Cheng JX. Gold nanorods as contrast agents for biological imaging: optical properties, surface conjugation and photothermal effects. Photochem Photobiol. 2009;85(1):21-32.

4. Huang X, Jain PK, El-Sayed IH, El-Sayed MA. Gold nanoparticles: interesting optical properties and recent applications in cancer diagnostics and therapy. Nanomedicine (Lond). 2007;2(5):681-693.

5. Fang J, Chen YC. Nanomaterials for photohyperthermia: a review. Curr Pharm Des. 2013;19(37):6622-6634.

6. Tromberg BJ, Shah N, Lanning R, et al. Non-invasive in vivo characterization of breast tumors using photon migration spectroscopy. Neoplasia. 2000;2(1-2):26-40.

7. Arvizo R, Bhattacharya R, Mukherjee P. Gold nanoparticles: opportunities and challenges in nanomedicine. Expert Opin Drug Deliv. 2010;7(6):753-763.

8. Chithrani BD, Ghazani AA, Chan WC. Determining the size and shape dependence of gold nanoparticle uptake into mammalian cells. Nano Lett. 2006;6(4):662-668.

9. Wang L, Li YF, Zhou L, et al. Characterization of gold nanorods in vivo by integrated analytical techniques: their uptake, retention, and chemical forms. Anal Bioanal Chem. 2010;396(3):1105-1114.

10. Ferrari M. Cancer nanotechnology: opportunities and challenges. Nat Rev Cancer. 2005;5(3):161-171.

11. Joshi PP, Yoon SJ, Hardin WG, Emelianov S, Sokolov KV. Conjugation of antibodies to gold nanorods through Fc portion: synthesis and molecular specific imaging. Bioconjug Chem. 2013;24(6):878-888.

12. Liopo A, Conjusteau A, Tsyboulski D, Ermolinsky B, Kazansky A, Oraevsky A. Biocompatible gold nanorod conjugates for preclinical biomedical research. J Nanomed Nanotechnol. 2012;S2:1-41.

13. Ludovini V, Flacco A, Bianconi F, et al. Concomitant high gene copy number and protein overexpression of IGF1R and EGFR negatively affect disease-free survival of surgically resected non-small-cell-lung cancer patients. Cancer Chemother Pharmacol. 2013;71(3):671-680.

14. Stumm G, Eberwein S, Rostock-Wolf S, et al. Concomitant overexpression of the EGFR and erbB-2 genes in renal cell carcinoma (RCC) is correlated with dedifferentiation and metastasis. Int J Cancer. 1996;69(1):17-22.

15. Hirsch FR, Varella-Garcia M, Cappuzzo F. Predictive value of EGFR and HER2 overexpression in advanced non-small-cell lung cancer. Oncogene. 2009;28 Suppl 1:S32-S37.

16. Jimeno A, Rubio-Viqueira B, Amador ML, et al. Epidermal growth factor receptor dynamics influences response to epidermal growth factor receptor targeted agents. Cancer Res. 2005;65(8):3003-3010.

17. Gschwind A, Fischer OM, Ullrich A. The discovery of receptor tyrosine kinases: targets for cancer therapy. Nat Rev Cancer. 2004;4(5): 361-370.
18. Arteaga CL, Truica CI. Challenges in the development of anti-epidermal growth factor receptor therapies in breast cancer. Semin Oncol. 2004;31(1 Suppl 3):S3-S8.

19. Sorkin A. Internalization of the epidermal growth factor receptor: role in signalling. Biochem Soc Trans. 2001;29(Pt 4):480-484.

20. Zhou Y, Drummond DC, Zou H, et al. Impact of single-chain Fv antibody fragment affinity on nanoparticle targeting of epidermal growth factor receptor-expressing tumor cells. J Mol Biol. 2007;371(4):934-947.

21. Black KC, Yi J, Rivera JG, Zelasko-Leon DC, Messersmith PB. Polydopamine-enabled surface functionalization of gold nanorods for cancer cell-targeted imaging and photothermal therapy. Nanomedicine (Lond). 2013;8(1):17-28.

22. Charan S, Sanjiv K, Singh N, et al. Development of chitosan oligosaccharide-modified gold nanorods for in vivo targeted delivery and noninvasive imaging by NIR irradiation. Bioconjug Chem. 2012;23(11):2173-2182.

23. Rejiya CS, Kumar J, Raji V, Vibin M, Abraham A. Laser immunotherapy with gold nanorods causes selective killing of tumour cells. Pharmacol Res. 2012;65(2):261-269.

24. Creixell M, Bohórquez AC, Torres-Lugo M, Rinaldi C. EGFR-targeted magnetic nanoparticle heaters kill cancer cells without a perceptible temperature rise. ACS Nano. 2011;5(9):7124-7129.

25. Domenech M, Marrero-Berrios I, Torres-Lugo M, Rinaldi C. Lysosomal membrane permeabilization by targeted magnetic nanoparticles in alternating magnetic fields. ACS Nano. 2013;7(6):5091-5101.

26. Voutilainen A, Tuovinen P. Treatment of laryngeal cancer and its results. A review of 261 cases. Ann Chir Gynaecol Fenn. 1962;51:14-26.

27. Rudolph E, Dyckhoff G, Becher H, Dietz A, Ramroth H. Effects of tumour stage, comorbidity and therapy on survival of laryngeal cancer patients: a systematic review and a meta-analysis. Eur Arch Otorhinolaryngol. 2011;268(2):165-179.

28. Kashima HK. The characteristics of laryngeal cancer correlating with cervical lymph node metastasis. Can J Otolaryngol. 1975;4(5):893-902.

29. Kowalski LP. Lymph node metastasis as a prognostic factor in laryngeal cancer. Rev Paul Med. 1993;111(4):42-45.

30. Moubayed SP, Bélair M, Saliba J, et al. Prognostic value of cartilage sclerosis in laryngeal cancer treated with primary radiation therapy. Otolaryngol Head Neck Surg. 2012;147(1):57-62.

31. Taki S, Homma A, Suzuki F, et al. Combined modality therapy for laryngeal cancer with superselective intra-arterial cisplatin infusion and concomitant radiotherapy. Int J Clin Oncol. 2012;17(5):441-446.

32. Agra IM, Ferlito A, Takes RP, et al. Diagnosis and treatment of recurrent laryngeal cancer following initial nonsurgical therapy. Head Neck. 2012;34(5):727-735.

33. Rubin Grandis J, Melhem MF, Gooding WE, et al. Levels of TGFalpha and EGFR protein in head and neck squamous cell carcinoma and patient survival. J Natl Cancer Inst. 1998;90(11):824-832.

34. Wei Q, Sheng L, Shui Y, Hu Q, Nordgren H, Carlsson J. EGFR, HER2, and HER3 expression in laryngeal primary tumors and corresponding metastases. Ann Surg Oncol. 2008;15(4):1193-1201.

35. Zimmermann M, Zouhair A, Azria D, Ozsahin M. The epidermal growth factor receptor (EGFR) in head and neck cancer: its role and treatment implications. Radiat Oncol. 2006;1:11.

36. Huang X, El-Sayed IH, Qian W, El-Sayed MA. Cancer cell imaging and photothermal therapy in the near-infrared region by using gold nanorods. J Am Chem Soc. 2006;128(6):2115-2120.

37. Sau TK, Murphy CJ. Seeded high yield synthesis of short Au nanorods in aqueous solution. Langmuir. 2004;20(15):6414-6420.

38. Smith DK, Korgel BA. The importance of the CTAB surfactant on the colloidal seed-mediated synthesis of gold nanorods. Langmuir. 2008;24(3):644-649.

39. Nikoobakht B, El-Sayed MA. Preparation and growth mechanism of gold nanorods (NRs)using seed-mediated growth method. Chem Mater. 2003;15(10):1957-1962.

40. Vieira AV, Lamaze C, Schmid SL. Control of EGF receptor signaling by clathrin-mediated endocytosis. Science. 1996;274(5295):2086-2089. 
41. Pissuwan D, Valenzuela SM, Killingsworth MC, Xu X, Cortie MB. Targeted destruction of murine macrophage cells with bioconjugated gold nanorods. J Nanopart Res. 2007;9(6):1109-1124.

42. Niidome T. Development of functional gold nanorods for bioimaging and photothermal therapy. J Phys: Conf Ser. 2010;232:1-6.

43. Decaudin D, Marzo I, Brenner C, Kroemer G. Mitochondria in chemotherapy-induced apoptosis: a prospective novel target of cancer therapy (review). Int J Oncol. 1998;12(1):141-152.

44. Jeong SY, Seol DW. The role of mitochondria in apoptosis. BMB Rep. 2008;41(1):11-22.
45. Hu S, Haj-Yehia A, Levi-Schaffer F. Role of reactive oxygen species (ROS) in apoptosis induction. Apoptosis. 2000;5(5):415-418.

46. Kondo Y, Kanzawa T, Sawaya R, Kondo S. The role of autophagy in cancer development and response to therapy. Nat Rev Cancer. 2005;5(9):726-734.

47. Zhang Y, Calderwood SK. Autophagy, protein aggregation and hyperthermia: a mini-review. Int J Hyperthermia. 2011;27(5):409-414.

48. Komata T, Kanzawa T, Nashimoto T, et al. Mild heat shock induces autophagic growth arrest, but not apoptosis in U251-MG and U87-MG human malignant glioma cells. J Neurooncol. 2004;68(2):101-111. 


\section{Supplementary material}

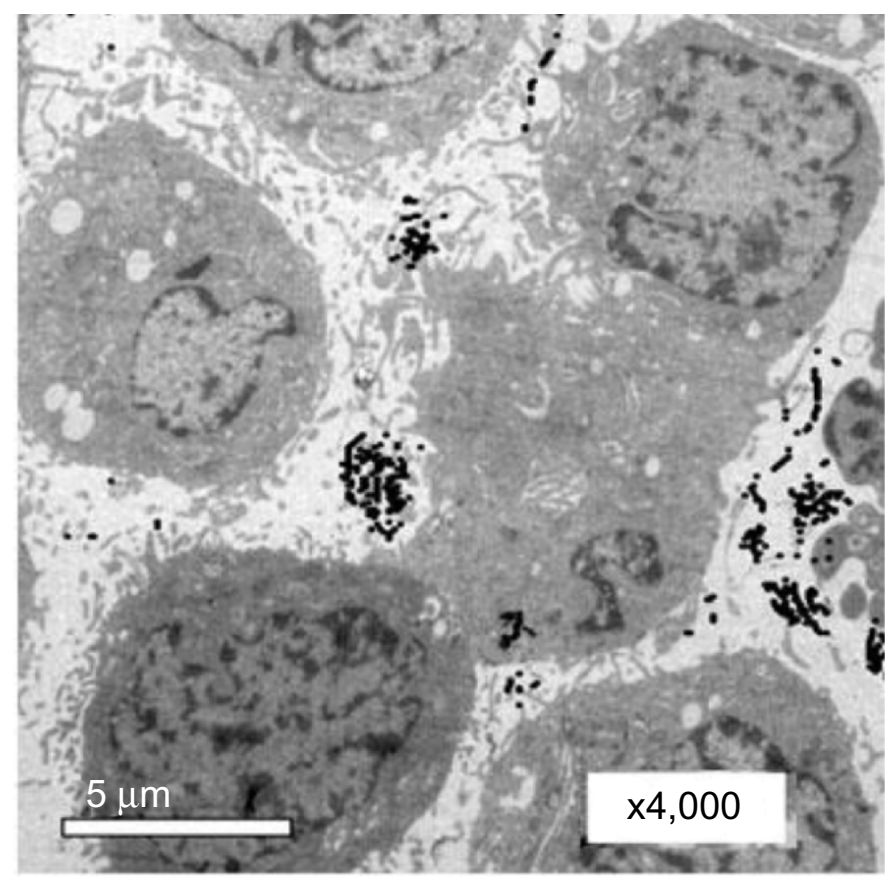

Figure SI TEM images of Hep-2 cells incubated with 0.1 nmol/L EGFRmAb-AuNRs for 30 minutes. EGFRmAb-AuNRs accumulated on the membrane of Hep- 2 cells. Abbreviations: AuNR, gold nanorod; EGFR, epidermal growth factor receptor; EGFRmAb, anti-EGFR monoclonal antibody; TEM, transmission electron microscope. 
A
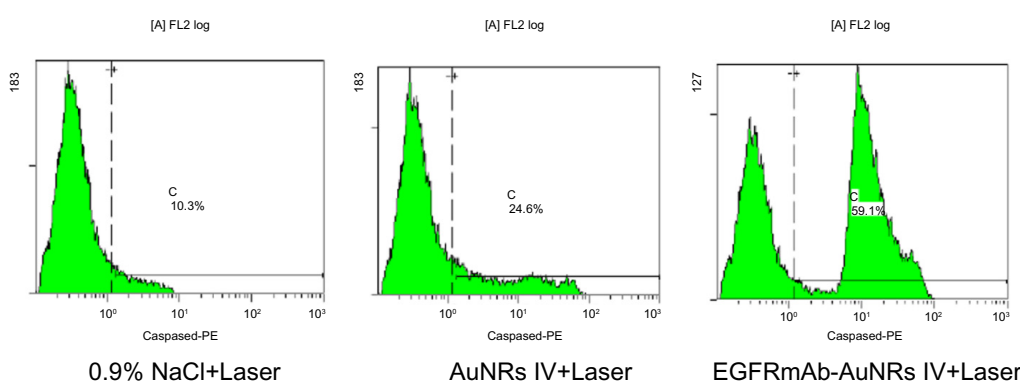

$0.9 \% \mathrm{NaCl}+$ Laser

AuNRs IV+Laser

EGFRmAb-AuNRs IV+Laser

Active caspase-3 expression in vitro tumor

B

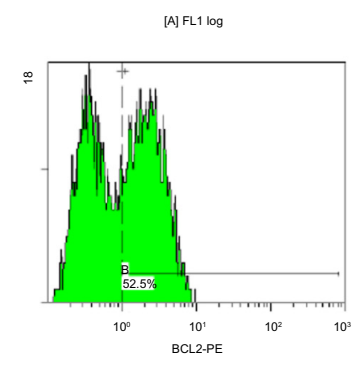

$0.9 \% \mathrm{NaCl}+$ Laser

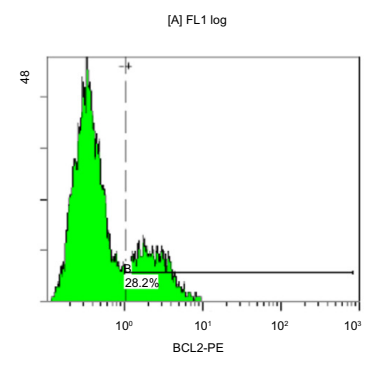

AuNRs IV+Laser

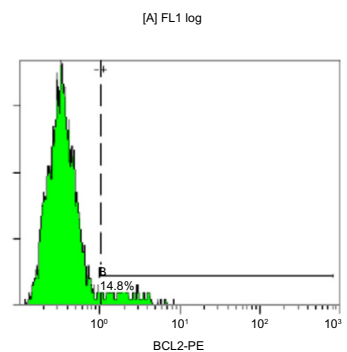

EGFRmAb-AuNRs IV+Laser

$\mathrm{Bcl}-2$ expression in vitro tumor

C

[A] FL1 log

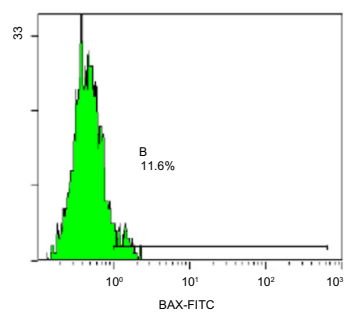

$0.9 \% \mathrm{NaCl}+$ Laser
[A] FL1 $\log$

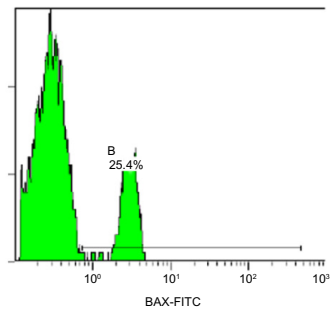

AuNRs IV+Laser

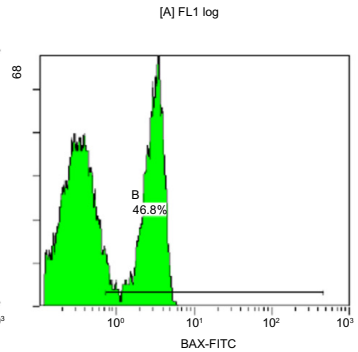

EGFRmAb-AuNRs IV+Laser

Bax expression in vitro tumor

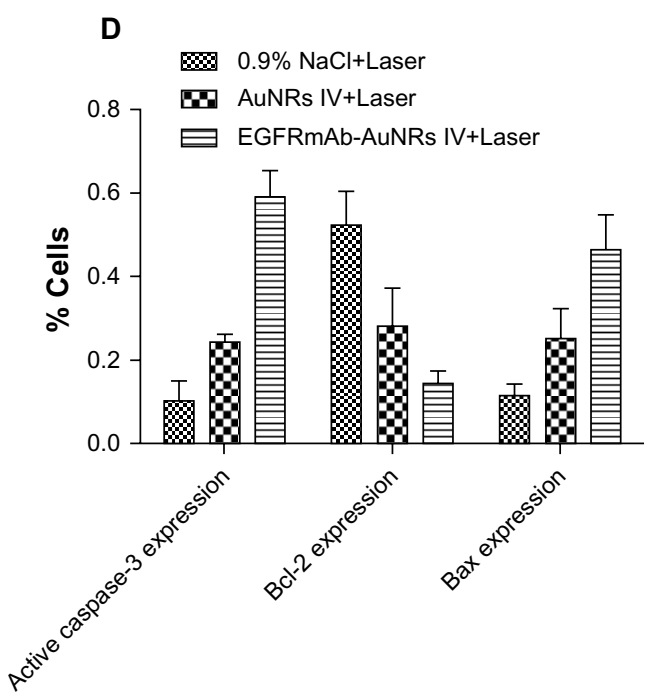

Figure S2 (A-C) FCM images of expression of active caspase-3, Bax and Bcl-2 in one vitro tumor. (D) Expression of active caspase-3, Bax and Bcl-2 in all vitro tumors ( $\mathrm{n}=6$ ). Abbreviations: AuNR, gold nanorod; Bax, Bcl-2-associated X protein; Bcl-2, B-cell lymphoma 2 protein; EGFR, epidermal growth factor receptor; EGFRmAb, anti-EGFR monoclonal antibody; FCM, flow cytometry. 


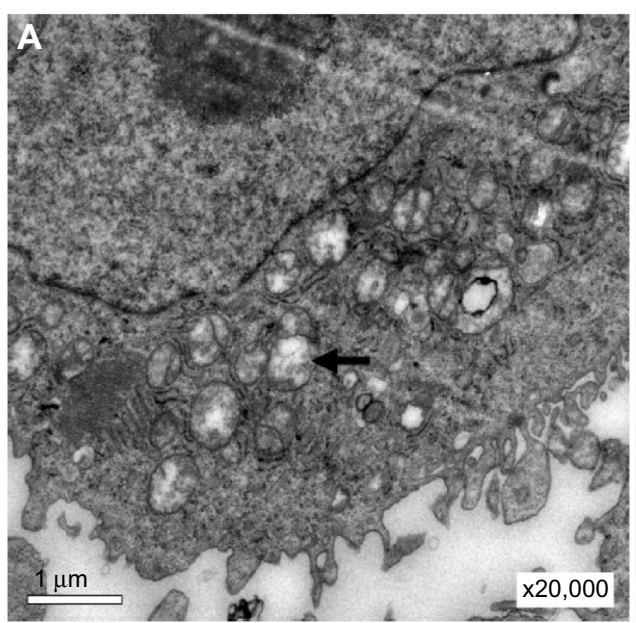

AuNRs+Laser

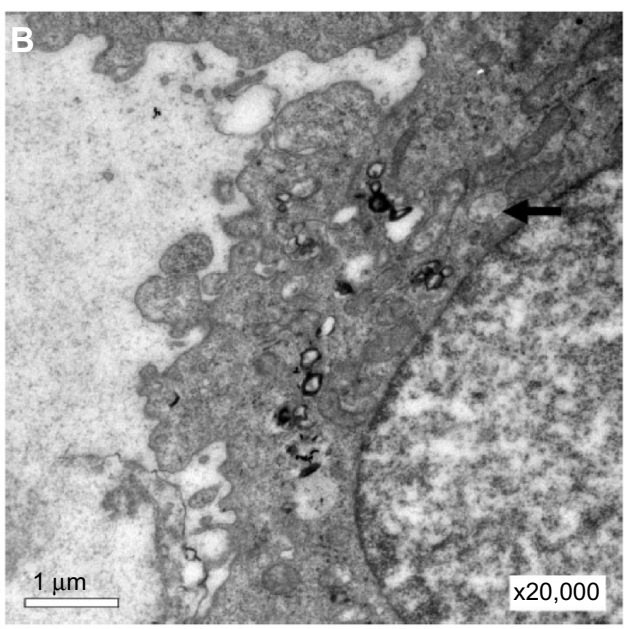

EGFRmAb-AuNRs+Laser

Figure S3 The autophagic structures (vacuolar components and secondary-lysosomes) in Hep-2 cells treated with (A) AuNRs+Laser, or (B) EGFRmAb-AuNRs+Laser, by TEM analysis.

Note: Hep-2 cells were treated with AuNRs+Laser or EGFRmAb-AuNRs+Laser, and the irradiated cells, at 24 hours, were collected for TEM analysis.

Abbreviations: AuNR, gold nanorod; EGFR, epidermal growth factor receptor; EGFRmAb, anti-EGFR monoclonal antibody; TEM, transmission electron microscope.

\section{Publish your work in this journal}

The International Journal of Nanomedicine is an international, peerreviewed journal focusing on the application of nanotechnology in diagnostics, therapeutics, and drug delivery systems throughout the biomedical field. This journal is indexed on PubMed Central, MedLine, CAS, SciSearch ${ }^{\circledR}$, Current Contents ${ }^{\circledR} /$ Clinical Medicine,
Journal Citation Reports/Science Edition, EMBase, Scopus and the Elsevier Bibliographic databases. The manuscript management system is completely online and includes a very quick and fair peer-review system, which is all easy to use. Visit http://www.dovepress.com/ testimonials.php to read real quotes from published authors. 